\title{
Early detection of response to hydroxyurea therapy in patients with sickle cell anemia.
}

\author{
Samir K. Ballas \\ Cardeza Foundation for Hematologic Research, Department of Medicine, Jefferson Medical College, \\ Thomas Jefferson University \\ William F. McCarthy \\ Maryland Medical Research Institute, Baltimore, MD \\ Nan Guo \\ Maryland Medical Research Institute, Baltimore, MD \\ Carlo Brugnara \\ The Children's Hospital, Boston, MA \\ Gajl Kling \\ Sillow this and additional works at: https.//jdc.jefferson.edu/medfp \\ Part of the Medical Genetics Commons \\ Let us know, how access to this document benefits you
see mext page for additional autinors
}

\section{Recommended Citation}

Ballas, Samir K.; McCarthy, William F.; Guo, Nan; Brugnara, Carlo; Kling, Gail; Bauserman, Robert L.; and Waclawiw, Myron A., "Early detection of response to hydroxyurea therapy in patients with sickle cell anemia." (2010). Department of Medicine Faculty Papers. Paper 49.

https://jdc.jefferson.edu/medfp/49

This Article is brought to you for free and open access by the Jefferson Digital Commons. The Jefferson Digital Commons is a service of Thomas Jefferson University's Center for Teaching and Learning (CTL). The Commons is a showcase for Jefferson books and journals, peer-reviewed scholarly publications, unique historical collections from the University archives, and teaching tools. The Jefferson Digital Commons allows researchers and interested readers anywhere in the world to learn about and keep up to date with Jefferson scholarship. This article has been accepted for inclusion in Department of Medicine Faculty Papers by an authorized administrator of the Jefferson Digital Commons. For more information, please contact: JeffersonDigitalCommons@jefferson.edu. 


\section{Authors}

Samir K. Ballas, William F. McCarthy, Nan Guo, Carlo Brugnara, Gail Kling, Robert L. Bauserman, and Myron A. Waclawiw 


\title{
As submitted to:
}

\author{
Hemoglobin
}

\author{
And later published as:
}

\section{"Early detection of response to hydroxyurea therapy in patients with sickle cell anemia"}

\section{Volume 34, Issue 5, October 2010, Pages 424-429}

\section{DOI: $10.3109 / 03630269.2010 .513638$}

Samir K. Ballas ${ }^{1}$, William F. McCarthy ${ }^{2}$, Nan $\mathrm{Guo}^{2}$, Carlo Brugnara ${ }^{3}$, Gail Kling $^{4}$, Robert L. Bauserman ${ }^{2}$, Myron A.Waclawiw ${ }^{5}$

${ }^{1}$ Cardeza Foundation for Hematologic Research, Department of Medicine, Jefferson Medical College, Thomas Jefferson University, Philadelphia, PA USA, ${ }^{2}$ Maryland Medical Research Institute, Baltimore, MD USA, ${ }^{3}$ The Children's Hospital, Boston, MA, USA, ${ }^{4}$ Siemens Healthcare Diagnostics Inc., Tarrytown, NY USA, ${ }^{5}$ National Heart, Lung and Blood Institute, Bethesda, Maryland, USA 
Corresponding author: Samir K. Ballas MD, FACP, Cardeza Foundation, Department of Medicine, Jefferson Medical College, Thomas Jefferson University, 1015 walnut Street, Philadelphia, PA 19107, Phone: 215-955-8485, Fax: 856-795- 0809, E-mail: samir.ballas@jefferson.edu

Shortened title: Early signs of response to hydroxyurea

\title{
Text word count: 1099
} Abstract word count: 148

\begin{abstract}
Red blood cells and reticulocyte parameters were determined on peripheral blood from a subset of patients enrolled in the Multicenter Study of Hydroxyuea_in_sickle cell anemia. Multiple blood samples were obtained every two weeks. Cellular indices were measured by flow cytometry. Generalized linear models were used to determine the relationship between the longitudinal trajectories of red blood cell and reticulocyte indices and hydroxyurea usage. There was a significant relationship between hydroxyurea usage and most of the red blood cell and reticulocyte indices. Hydroxyurea produced higher value trajectories than those generated by placebo usage for the hemoglobin content of both the red blood cells and reticulocytes and for the mean corpuscular volume of
\end{abstract}


reticulocytes. These changes were first detected 10 weeks after starting hydroxyurea and before the increase in hemoglobin F levels. The data suggest that subtle and early markers of response to hydroxyurea reside in the hemogram.

Key words: Hydroxyurea, Sickle cell anemia, Reticulocytes, Responders, Indices 


\section{Introduction}

The salutary effects of hydroxyurea (HU) in sickle cell anemia (SS) include decreased frequency of painful crises, decreased incidence of acute chest syndrome, decreased blood transfusion, and decreased mortality and morbidity (1-5). Markers of the response to $\mathrm{HU}$ include increased $\mathrm{Hb} \mathrm{F}$ level, macrocytosis, improved RBC survival and deformability, and decreased WBC count (!-7). In this study we report markers of early response to HU by using generalized linear mixed models (GLM) to determine the relationship between $\mathrm{HU}$ usage and the longitudinal trajectories of $\mathrm{RBC}$ indices and the corresponding longitudinal trajectories of reticulocytes indices. 


\section{Methods}

$\mathrm{RBC}$ and reticulocyte parameters were determined on peripheral blood from selected patients enrolled in the placebo (PL) controlled double blind multicenter study of hydroxyuea (MSH) in SS. The study cohort for this analysis consisted of 21 patients from the Thomas Jefferson University, Cardeza Foundation for Hematologic Research (10 HU subjects, 11 PL subjects). Multiple blood samples were obtained during enrollment in the study at a rate of about once every two weeks. The mean weeks of follow-up from enrollment date was 86.6 weeks (range 10-172 weeks). The RBC/PLT channel of the Siemens $H^{*} 3 \mathrm{RTX}\left(\mathrm{H}^{*} 3\right)$ hematology analyzer measures the laser light scattered at 2 different angles by red cells which have been isovolumetrically sphered. Using the Mie theory of light scatter the low angle $\left(2-3^{\circ}\right)$ light intensity directly measures $\mathrm{RBC}$ volume (MCV, femtoliters) and the high angle $\left(5-15^{\circ}\right)$ light intensity directly measures refractive index which is a linear function of red cell hemoglobin concentration (CHCM, cell hemoglobin concentration mean, grams per deciliter). The Reticulocyte channel reagent also isovolumetrically spheres as well as selectively staining the reticulocytes with the nucleic acid-binding dye Oxazine 750. Using the same laser optics and principles as the RBC/PLT channel, reticulocyte volume (MCVr, femtoliters) and reticulocyte hemoglobin concentration (CHCMr, grams per decilter) are directly measured. An additional detector measures laser light absorption by the Oxazine 750 dye to separate the reticulocytes from the mature red cells. The RBC/PLT channel measures the mean hemoglobin content of the red cells $(\mathrm{CH})$ and the reticulocyte channel measures the mean hemoglobin content of the reticulocytes $(\mathrm{CHr})$ by multiplying the volume and the cell hemoglobin concentration 
mean. RBC and Reticulocyte indices were measured on a Siemens H*3 RTX (H*3) hematology analyzer. Laser light scattering was used to quantify cell volume, $\mathrm{Hb}$ concentration, and the light absorbance of cells stained with oxazine 750 to detect reticulocytes and distinguish them from mature cells. A total of 20,000 cells were counted for each sample. After the volume (V) and Hb concentration (HC) of individual mature $\mathrm{RBC}$ and reticulocytes were measured, the $\mathrm{Hb}$ content $(\mathrm{CH})$ of individual cells was calculated (8).

Generalized linear mixed models (GLM) were used to determine the relationship between the longitudinal trajectories of RBC and reticulocyte indices and HU usage (9-12). A first-order autoregressive structure was used (1). Information criteria [Akaike Information Criterion (AIC)] (13), Akaike Information Criterion, Small Sample Size Corrected Version (AICC) (14) and the Bayesian Information Criterion (BIC) (15) were used to compare and determine which GLM provided better insight into the relationship between the longitudinal trajectories of RBC and reticulocyte indices and HU usage. The information criteria are all in "smaller-is-better" form. Since the GLM considered longitudinal data,the time at which the longitudinal trajectories were influenced by HU usage could also be determined. PROC MIXED (SAS 9.1) was used for the GLM analyses. Statistical significance was defined as a 2-sided p-value <.05. 


\section{Results}

The mean weeks (wks) of follow-up from study enrollment date was 86.6 wks (standard deviation $(\mathrm{sd})=38.84 \mathrm{wks} ; \max =172 \mathrm{wks}$, median $=84 \mathrm{wks}, \min =10 \mathrm{wks})$. The mean age of this patient cohort at the start of follow-up was 29.0 years $(\mathrm{SD}=4.77$ years; $\max =37$ years, median $=30$ years, $\min =19$ years $)$. There were 13 males $(61.9 \%)$ and 8 females $(38.1 \%)$.

Goodness-of-fit criteria for the GLM indicated that the RBC indices modeled more precisely than those of reticulocytes. However, both the RBC indices and reticulocytes provided useful information regarding the relationship between their longitudinal trajectories and HU usage (Table 1).

There was a significant relationship between HU usage and the following longitudinal trajectories: mean cell hemoglobin $(\mathrm{CH})(\mathrm{p}<.0001)$, reticulocyte mean cell hemoglobin $(\mathrm{CHr})(\mathrm{p}<.0001)$; Cell hemoglobin concentration mean $(\mathrm{CHCM})(\mathrm{p}=.0394)$; Reticulocyte mean cell volume (MCVr) (p=.0019); hemoglobin distribution width (HDW) (p=.0003) and red blood cell volume distribution width (RDW) ( $\mathrm{p}=.0008)$. HU usage produced higher value trajectories than those generated by placebo usage for the following: $\mathrm{CH}$, CHr; and MCVr (Fig. 1). These changes were first detected 10 weeks after starting HU and before the increase in $\mathrm{Hb} \mathrm{F}$ levels. 


\section{Discussion}

Although HU has been proven to have salutary effects in patients with SS (1-3) its utilization continues to suffer from two major drawbacks. These include its underutilization (16) and the fact that at least $25 \%$ of patients who take it are nonresponders to its use $(1,2)$. These two drawbacks seem to re-enforce each other. Thus some patients may be falsely labeled as non-responders if no effect on frequency of painful crises and/or no increase in the level of $\mathrm{Hb} \mathrm{F}$ is seen within 2-3 months after starting $\mathrm{HU}$ at a dose of $10-15 \mathrm{mg} / \mathrm{k} /$ day. The reason why some patients do not respond to $\mathrm{HU}$ is unknown. One possibility is that it fails to recruit dormant bone marrow fetal stem cells that are capable to produce fetal $\mathrm{Hb}$. Moreover, it usually takes at least six months of therapy with $\mathrm{HU}$ before an increase in $\mathrm{Hb} \mathrm{F}$ is seen (7). Thus an early sign of a response-in-progress to HU therapy is important information for the provider who is monitoring the the clinical and hematological data of patients after the initiation of therapy with HU.

In this study we report markers of early response to HU by using generalized linear mixed models (GLM) to determine the relationship between HU usage and the longitudinal trajectories of RBC parameters and the corresponding longitudinal trajectories of reticulocytes parameters. Specifically HU therapy showed significant changes in the $\mathrm{Hb}$ content $(\mathrm{CHr})$ and cell volume of reticulocyte (MCVr) compared to placebo within 10 weeks after starting HU indicating an early sign of response to therapy. 
Thus the sequence of signs of response to HU include increase in reticulocyte indices (CHr and MCVr) within 10 weeks after therapy followed by increase in RBC indices and a later increase (up to six months) in $\mathrm{Hb} \mathrm{F}$ level.

\section{Conclusion}

Together the data suggest that subtle and early markers of response to HU reside in the hemogram. This is a fast, simple and inexpensive methodology provided the lab in question has the capability to determine the indices of both reticulocytes and RBC.

Acknowledgement: Supported in part by The National Heart, Lung and Blood Institute (NO1-HB-67129 and UO1-HL45696) and in part by the Sickle Cell Program of the Commonwealth of Pennsylvania for the Philadelphia region

Conflict of interest: The authors report no potential conflicts of interest. 


\section{References}

1. Charache S, Dover GJ, Moore RD, et al. Hydroxyurea: Effects on Hemoglobin F Production in Patients with Sickle Cell Anemia. Blood 1992;79:2555-65.

2. Charache S, Terrin ML, Moore RD, et al. Effect of hydroxyurea on the frequency of painful crises in sickle cell anemia. N Engl J Med. 1995;332:1317-22.

3. Charache S, Barton, FB, Moore, RD, et al.Hydroxyurea, and sickle cell anemia. Clinical utility of a hemoglobin "switching" agent. The Multicenter Study of Hydroxyurea in Sickle Cell Anemia. Medicine 1996;75:300-26.

4. Steinberg MH, Lu ZH, Barton FB, et al. Fetal hemoglobin in sickle cell anemia: determinants of Response to Hydroxyurea. Blood 1997;89:1078-88.

5. Steinberg MH, Barton F, Castro O, et al. Effect of Hydroxyurea on Mortality and Morbidity in Adult Sickle Cell Anemia: Risks and Benefits up to 9 Years of Treatment. JAMA 2003;289:1645-51.

6. Ballas SK, Marcolina MJ, Dover GJ, et al. Erythropoietic activity in patients with sickle cell anemia before and after treatment with Hydroxyurea. Brit J Haematol 1999;105:491-96.

7. Ballas SK, Dover GJ, Charache S. Effect of Hydroxyurea on the reheological properties of sickle erythrocytes in vivo. Am. J. Hematol. 32:104-111, 1989.

8. Brugnara C, Zelmanovic D, Sorette M, et al. Reticulocyte hemoglobin (ret $\mathrm{Hb}$ ): An integrated parameter for evaluation of erythropoietic activity. Am. J. Clin. Pathol 1997;108:133-42.

9. Littell RC, Milliken GA, Stroup WW, et al. SAS System for Mixed Models 1996;Cary, NC: SAS Institute Inc.

10. Verbeke G. and Molenberghs G, eds. Linear Mixed Models in Practice: A SASOriented Approach 1997; New York: Springer. 
11. Verbeke G. and Molenberghs G. Linear Mixed Models for Longitudinal Data. 2000; New York: Springer.

12. Brown H. and Prescott R. Applied Mixed Models in Medicine, 1999; New York: John Wiley \& Sons, Inc.

13. . Akaike H. A New Look at the Statistical Model Identification, IEEE Transaction on Automatic Control 1974; AC - 19, 716 - 723.

14. Hurvich CM.,Tsai, C.-L. Regression and Time Series Model Selection in Small Samples. Biometrika, 1989;76: 297 - 07.

15. Schwarz, G. Estimating the Dimension of a Model. Annals of Statistics 1978;6:461 64.

16. Lanzkron S, Haywood C Jr, Segal JB. Et al.Hospitalization rates and costs of care of patients with sickle-cell anemia in the state of Maryland in the era of hydroxyurea. Am J Hematol. 2006;81:927-32.

\section{Legend to Figure 1}


Time trends in MCV and MCVr by treatment assignment 